\title{
Prostatic Bleeding after Prostatic Biopsy Effects Oncological Outcomes with Laparoscopic Radical Prostatectomy
}

\author{
Tomoaki Takai ${ }^{1 *}$, Teruo Inamoto ${ }^{1}$, Kazumasa Komura ${ }^{1}$, Takuya Tsujino ${ }^{1}$, \\ Tomohisa Matsunaga ${ }^{1}$, Yuki Yoshikawa ${ }^{1}$, Taizo Uchimoto ${ }^{1}$, Kenkichi Saito', \\ Naoki Tanda ${ }^{1}$, Koichiro Minami ${ }^{1}$, Hirofumi Uehara ${ }^{1}$, Naokazu Ibuki ${ }^{2}$, Kiyoshi \\ Takahara $^{1}$, Hayahito Nomi ${ }^{1}$, Satoshi Kiyama ${ }^{1}$, Hayahito Azuma ${ }^{1}$
}

\begin{abstract}
Background: We vigorously reviewed patients' operation record who had adhesion of the Denonvilliers' fascia and found out most of these patients had prostatic bleeding after prostatic gland biopsies. We examined the magnitude of prostatic bleeding and frequency after biopsies and the relationship with oncological outcomes. Materials and Methods: A total of $\mathbf{2 8 5}$ patients were selected for the final analyses. Inclusion criteria were as follows: receiving MRI three weeks after biopsiesand laparoscopic radical prostatectomy within 300 days after biopsy. We divided the patients into two groups with (group A) or without (group B) prostatic bleeding. We examined the magnitude of prostatic bleeding after biopsies and the relationship with operation time (OT), positive surgical margin (PSM), biochemical recurrence (BCR) and other factors. Furthermore, we created a logistic-regression model to derive a propensity score for prostatic bleeding after biopsies, which included all patient and hospital characteristics as well as selected interaction terms, and we examined the relationship with PSM and BCR. Results: In all patients, the OT in the group B was shorter than the group $A(p<0.001)$. Prostatic bleeding was associated with PSM $(p=0.000)$ and $B C R(p=0.036)$. In this propensity-matched cohort, 11 of 116 patients in the group B had PSM as compared with 36 of 116 patients from group A (match-adjusted odds ratio, 4.30; 95\% CI confidence interval, 2.06 to 8.96; $\mathrm{P}=0.000$ ). In addition, eight of 116 patients in group $B$ encountered BCR, as compared with 18 of 116 patients in group A (match-adjusted odds ratio, 2.48; 95\% CI, 1.03 to 5.96; $P=0.042$ ). Kaplan-Meier analysis in the propensity matching cohort showed a significant biochemical recurrence-free survival advantage for being free of prostate bleeding after biopsies. Conclusions: Our findings in the present cohort should help equip surgeons to pay attention to careful excision especially for those who experienced deferred prostatic bleeding.
\end{abstract}

Keywords: Prostate cancer - laparoscopic radical prostatectomy - biopsy - MRI - bleeding

Asian Pac J Cancer Prev, 17 (3), 1373-1377

\section{Introduction}

Prostate cancer $(\mathrm{PCa})$ is the most commonly diagnosed solid malignancy in men. The majority of Pca is diagnosed as clinically localized disease due to widespread prostatespecific antigen (PSA) screening and resulting stage migration, and commonly accepted treatment options for localized disease including active surveillance, radical prostatectomy (RP), and radiotherapy.

In recent years, significant improvements have been made in the early detection of Pca. Open radical retropubic prostatectomy (ORRP), in particular, had been provided excellent long-term disease control for patients with clinically localized Pca. In the nineties, laparoscopy was expanded as a minimally invasive surgery in the world. The first laparoscopic RP (LRP) was done in 1991, by Schuessler et al. (1997) The first Robot-assisted laparoscopic radical prostatectomy (RALP) was first described in 2000 by Abbou et al. (2000) In these several years, LRP and RALP has rapidly spread as a minimally invasive surgery. LRP and more recently RALP, have become more common and represent an alternative to the conventional operation such as ORRP in many countries. RALP has gradually become to be widely accepted, LRP is intensively used in selected countries in Europe and Asia, including Japan, perhaps because of the cost matter - daVinci system has very high maintenance cost.

A widely acknowledged criterion for the technical quality of RP is the positive surgical margin (PSM) rate, and this rate has been shown to affect the risk of 


\section{Tomoaki Takai et al}

biochemical recurrence (BCR) after surgery. Although previous reports demonstrated predictors that may prolong operation time (OT) and raise the rate of positive surgical margin (PSM), there are no studies so far that evaluated the practical impact of adhesion of the Denonvilliers' fascia due to prostatic bleeding by biopsy procedure on the PSM rate. Peri-prostatic and/or intra-prostatic bleeding is one of the most common complications seen in of the biopsies for prostatic gland.

We reviewed patients' operation record who had adhesion of the Denonvilliers' fascia and found out most of these patients had prostatic bleeding after biopsies for prostatic gland. We examined the altitude of prostatic bleeding after biopsies for prostatic gland and the relationship with PSM and other factors.

\section{Materials and Methods}

We retrospectively reviewed a series of 356 patients who had undergone LRP at the Department of Urology, Osaka Medical College, Osaka, Japan between July 2007 and March 2013. Of the 356 patients, excluding 71 patients without MRI of the prostate after biopsies for prostatic gland. A series of 285 patients evaluated with MRI of the prostate straight after the prostate biopsy was reviewed and included in the analyses. Two radiology specialists double checked the finding of peri-prostatic plus intra-prostatic bleeding by routine fast spin echo at 3 tesla MRI and stratified patients into two groups depending on whether it encountered prostatic bleeding by the biopsy procedure or not. All LRP were carried out by an extraperitoneal approach and bilateral obturator lymph nodes were dissected.

All procedures were safely carried out without any severe complications or open conversion. Age, BMI, prostate volume, having or not prostatic stone, history of previous lower abdominal surgery, and D'Amico risk group were recorded. A patient who was overweight (25.0 $\mathrm{kg} / \mathrm{m} 2 \mathrm{BMI}<30.0 \mathrm{~kg} / \mathrm{m} 2$ ) or obese (BMI $30.0 \mathrm{~kg} / \mathrm{m} 2$ ) according to the WHO classification was defined as obese. Postsurgery follow-up visits typically were scheduled at 3-month intervals for a few years, and then semiannually for 1 year, and yearly thereafter. Patients were divided into two groups according to their prostate bleeding in MRI after biopsies for prostatic gland. We reviewed total operation time (OT) and amount of bleeding from medical records. And, the oncological outcomes were assessed as PSM and BCR rates. PSM was defined as tumor cells reaching the inked surface of the specimen. BCR was defined as two consecutive prostate-specific antigen (PSA) measurements $\geq 0.2 \mathrm{ng} / \mathrm{mL}$.

We used propensity-score matching to adjust for differences between patients who had prostatic bleeding and those who did not have prostatic bleeding and compared in OT, amount of bleeding, PSM and BCR. Chi-squared tests were used to analyze associations between categorical variables. Mann-Whitney U test was used for continuous variables, OT and amount of blood loss. Univariate and multivariate logistic regression were used to assess each of variables as predictors of PSM and BCR. Kaplan-Meier curve analysis was performed for biochemical recurrence free survival. All statistical analyses were performed using SPSS 20.0 (SPSS, Chicago, Illinois).

\section{Results}

The baseline characteristics of the 284 men, stratified by having or not prostate bleeding, are listed in Table 1 . 147 patients $(51.8 \%)$ had prostatic bleeding caused by biopsy (group A), while 137 patients (48.2\%) did not have prostatic bleeding (group B) in MRI checked by specialists review. No differences were found in median age, time to inspection from biopsy to MRI, clinical stage, prostate volume, BMI, operation career, and D'Amico risk among both groups. Statistically significant differences were noted between the two groups with regard to prostate stone ( $\mathrm{p}=0.030)$. The mean time to inspection from biopsy to MRI was 49.9 and 54.2 month respectively $(\mathrm{p}=0.512)$. The surgical outcomes of both groups are listed in Figure1. The operating time in the group B was shorter than the group A ( $p<0.001)$. There was no difference in median amount of blood loss $(\mathrm{p}=0.179)$. The prostate bleeding induces PSM $(p=0.000)$ and causes BCM $(p=0.036)$. In the Table 2, univariate and multivariate regression analyses of oncological outcomes showed that what predictor associated with PSM and BCR. Kaplan-Meier analysis of all patients shows a significant biochemical recurrencefree survival advantage of without prostate bleeding after biopsies for prostatic gland $(\mathrm{p}=0.020)$.

\section{Propensity score matching cohort}

Prostate biopsy-related change can persist for up to $4 \frac{1}{2}$ months after biopsy and, although it can be readily

\section{Table 1. Preoperative clinical date}

\begin{tabular}{|c|c|c|c|}
\hline Variable & $\begin{array}{c}\text { With } \\
\text { prostate } \\
\text { bleeding } \\
(\mathrm{n}=147)\end{array}$ & $\begin{array}{l}\text { Without } \\
\text { prostate } \\
\text { bleeding } \\
(\mathrm{n}=137)\end{array}$ & P-value \\
\hline Age(mean) & $52-79(69)$ & $55-81(69)$ & 0.678 \\
\hline \multicolumn{4}{|l|}{ Clinical stage } \\
\hline $\mathrm{T} 1$ & 73 & 68 & 0.462 \\
\hline $\mathrm{T} 2$ & 70 & 67 & 0.481 \\
\hline$>\mathrm{T} 3$ & 4 & 2 & \\
\hline \multicolumn{4}{|l|}{ Gleason score } \\
\hline$<6$ & 92 & 82 & 0.778 \\
\hline 7 & 38 & 36 & 0.227 \\
\hline$>8$ & 17 & 19 & \\
\hline \multicolumn{4}{|c|}{ Prostate specific antigen } \\
\hline$<10$ & 92 & 82 & 0.537 \\
\hline $10 \sim 20$ & 38 & 36 & 0.685 \\
\hline$>20$ & 17 & 19 & \\
\hline \multicolumn{4}{|l|}{ Operation career } \\
\hline Yes & 19 & 23 & 0.405 \\
\hline No & 128 & 114 & \\
\hline $\begin{array}{c}\text { Duration of biopsy } \\
\text { and MRI }\end{array}$ & $\begin{array}{c}8-428 \\
(42)\end{array}$ & $\begin{array}{l}10-920 \\
(44)\end{array}$ & 0.77 \\
\hline
\end{tabular}

MRI: magnetic resonance imaging 
Prostatic Bleeding after Biopsy Effects Oncological Outcomes with Laparoscopic Radical Prostatectomy

Table 2. Predictors of Surgical and Oncologic Outcomes of All Patients

\begin{tabular}{|c|c|c|c|c|c|c|c|c|c|c|c|c|}
\hline & \multicolumn{6}{|c|}{ Positive surgical margin } & \multicolumn{6}{|c|}{ Biochemical recurrence } \\
\hline & \multicolumn{3}{|c|}{$\begin{array}{c}\text { Univariate regression } \\
\text { analyses }\end{array}$} & \multicolumn{3}{|c|}{$\begin{array}{c}\text { Multivariate regression } \\
\text { analyses }\end{array}$} & \multicolumn{3}{|c|}{$\begin{array}{c}\text { Univariate regression } \\
\text { analyses }\end{array}$} & \multicolumn{3}{|c|}{$\begin{array}{c}\text { Multivariate regression } \\
\text { analyses }\end{array}$} \\
\hline Covariate & $\begin{array}{l}\text { Hazard } \\
\text { ratio }\end{array}$ & $\begin{array}{c}\mathrm{P} \\
\text { value }\end{array}$ & $95 \% \mathrm{CI}$ & $\begin{array}{l}\text { Hazard } \\
\text { ratio }\end{array}$ & $P$ value & $95 \% \mathrm{CI}$ & $\begin{array}{l}\text { Hazard } \\
\text { ratio }\end{array}$ & P value & $95 \% \mathrm{CI}$ & $\begin{array}{l}\text { Hazard } \\
\text { ratio }\end{array}$ & $\begin{array}{c}\mathrm{P} \\
\text { value }\end{array}$ & $95 \% \mathrm{CI}$ \\
\hline $\begin{array}{l}\text { Prostate } \\
\text { volime } \\
(35>\text { vs. } \geq 35)\end{array}$ & 0.98 & 0.955 & $\begin{array}{c}0.54- \\
1.78\end{array}$ & 0.93 & 0.843 & $\begin{array}{c}0.48- \\
1.83\end{array}$ & 1.41 & 0.325 & $\begin{array}{l}0.71- \\
2.83\end{array}$ & 1.22 & 0.605 & $\begin{array}{l}0.57- \\
2.63\end{array}$ \\
\hline $\begin{array}{l}\text { Body mass } \\
\text { index } \\
(25>\text { vs. } \geq 25)\end{array}$ & 0.63 & 0.209 & $\begin{array}{c}0.31- \\
1.29\end{array}$ & 0.60 & 0.188 & $\begin{array}{c}0.28- \\
1.28\end{array}$ & 0.90 & 0.797 & $\begin{array}{l}0.40- \\
2.01\end{array}$ & 0.87 & 0.733 & $\begin{array}{c}0.38- \\
1.98\end{array}$ \\
\hline Prostate stone & 1.16 & 0.627 & $\begin{array}{c}0.64- \\
2.09\end{array}$ & 1.06 & 0.855 & $\begin{array}{l}0.56- \\
2.01\end{array}$ & 1.54 & 0.221 & $\begin{array}{c}0.77- \\
3.09\end{array}$ & 1.45 & 0.321 & $\begin{array}{c}0.70- \\
3.00\end{array}$ \\
\hline $\begin{array}{l}\text { Prostate } \\
\text { bleeding }\end{array}$ & 3.98 & 0.000 & $\begin{array}{c}2.03- \\
7.79\end{array}$ & 4.12 & 0.000 & $\begin{array}{l}2.07- \\
8.21\end{array}$ & 2.46 & 0.018 & $\begin{array}{l}1.17- \\
5.20\end{array}$ & 2.48 & 0.020 & $\begin{array}{l}1.15- \\
5.35\end{array}$ \\
\hline $\begin{array}{l}\text { Abdominal } \\
\text { operation } \\
\text { career }\end{array}$ & 0.64 & 0.347 & $\begin{array}{c}0.26- \\
1.61\end{array}$ & 0.67 & 0.417 & $\begin{array}{c}0.25- \\
1.77\end{array}$ & 1.41 & 0.450 & $\begin{array}{l}0.58- \\
3.47\end{array}$ & 1.68 & 0.280 & $\begin{array}{l}0.66- \\
4.30\end{array}$ \\
\hline $\begin{array}{l}\text { D'Amico's } \\
\text { risk group } \\
\text { (low vs. } \\
\text { intermediate) }\end{array}$ & 1.53 & 0.189 & $\begin{array}{c}0.81- \\
2.90\end{array}$ & 1.35 & 0.376 & $\begin{array}{l}0.69- \\
2.64\end{array}$ & 1.70 & 0.173 & $\begin{array}{c}0.79- \\
3.66\end{array}$ & 1.55 & 0.276 & $\begin{array}{c}0.71- \\
3.39\end{array}$ \\
\hline $\begin{array}{l}\text { D'Amico's } \\
\text { risk group } \\
\text { (low vs. high) }\end{array}$ & 4.82 & 0.012 & $\begin{array}{l}1.41- \\
16.53\end{array}$ & 5.28 & 0.009 & $\begin{array}{l}1.50- \\
18.53\end{array}$ & 4.63 & 0.043 & $\begin{array}{l}10.50- \\
20.43\end{array}$ & 5.13 & 0.033 & $\begin{array}{l}1.14- \\
23.10\end{array}$ \\
\hline
\end{tabular}

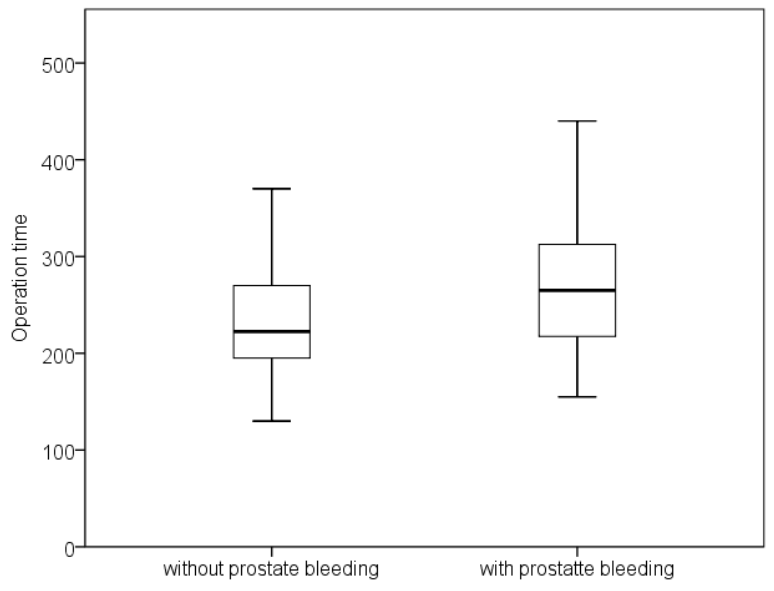

Figure 1. Operation Time of Patients without Prostate Bleeding after Biopsies for Prostatic Gland is Significantly Shorter Than Of Patients with Prostate Bleeding. $\mathrm{p}=\mathbf{0 . 0 0 0}$

identified by its high signal intensity on T1-weighted images, can compromise the interpretation of T2-weighted images because it can have a similar appearance to that of prostate cancer (low T2 signal intensity) in up to $80 \%$ of cases. The problem of prostate biopsy-related change has led some authors to recommend delaying MR imaging for 3-8 weeks after biopsy however, the disappearance of biopsy-related change is not readily definable for a given individual. So, we include 259 patients who were receive MRI from an examination of biopsies for prostatic gland after 21 st and patients who had LRP within 300 days in this sub analysis. We created a logistic-regression model

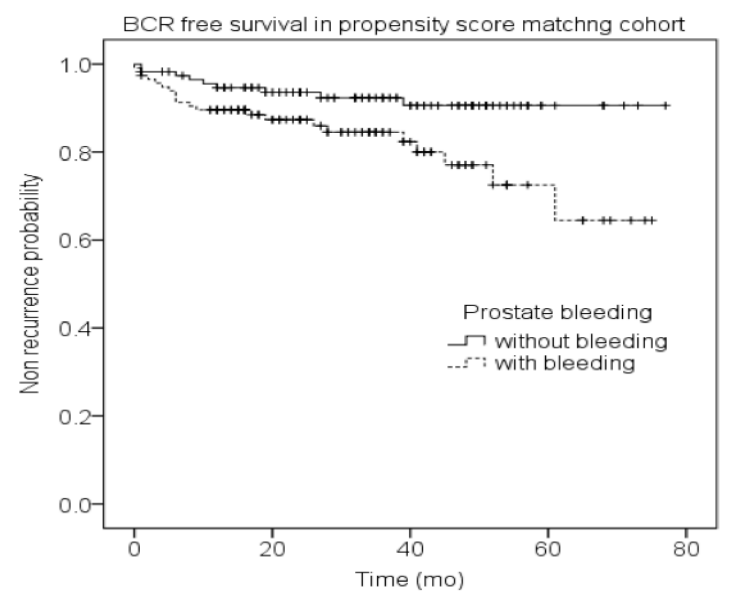

Figure 2. Biochemical recurrence (BCR) free survival in prostate bleeding after prostatic biopsy vs without prostate bleeding in propensity score matching cohort. $\mathbf{p}=\mathbf{0 . 0 3 7}$

to derive a propensity score for prostatic bleeding after biopsies for prostatic gland that included all patient and hospital characteristics as well as selected interaction terms. Each patient was assigned a propensity score that reflected the probability that they would have prostatic bleeding after biopsies for prostatic gland. Using a Greedy 5-to-1 digit-matching algorithm, we matched each patient who had prostatic bleeding after biopsies for prostatic gland with up to two patients who did not have prostatic bleeding, starting with all five-digit propensityscore matches before moving to those with four or fewer matches, in an iterative process. The matched cohort was 
evaluated for differences between treatment groups in each of the potential confounding factors, and conditional logistic regression was used to assess each of variables as predictors of PSM and BCR, after adjustment for any residual differences (given a $\mathrm{P}$ value of less than 0.01 ). We matched 116 patients who had prostatic bleeding after biopsies for prostate gland with at least one patient who did not have prostatic bleeding on the basis of the propensity score. In this propensity-matched cohort, 11 of 116 patients having prostatic bleeding after biopsies were induced PSM, as compared with 36 of 116 patients who did not have prostatic bleeding ( 9.5 percent $v s .31 .0$ percent; match-adjusted odds ratio, 4.30; 95 percent confidence interval, 2.06 to $8.96 ; \mathrm{P}=0.000$ ). And eight of 116 patients without prostate bleeding were caused BCR, as compared with 18 of 116 patients with prostate bleeding (6.7 percent vs. 15.5 percent; match-adjusted odds ratio, 2.48; 95 percent confidence interval, 1.03 to $5.96 ; \mathrm{P}=0.042$ ). In Figure2, Kaplan-Meier analysis in propensity matching cohort shows a significant biochemical recurrence-free survival advantage of without prostate bleeding after biopsies for prostatic gland.

\section{Discussion}

Traditionally, it has been recommended that RP should be deferred for at least 4-6 weeks after prostate biopsy, allowing an interval for the resolution of hematomas and adhesions from biopsy. It has been widely assumed that aftereffects of biopsy may eliminate surgical planes, making delicate procedures of RP, such as nerve-sparing, difficult. However, available literature offers no concrete evidences to support such delaying of surgery following biopsy. This study demonstrated that prostate bleeding after prostatic bleeding after biopsies for prostatic gland prolongs OT of LRP. And, it causes PSM easier than without prostatic bleeding after biopsy for prostatic gland.

In recent years, several reports have described the technical feasibility and oncologic efficacy of LRP and RALP in obese men (Brown et al., 2005; Boczko et al., 2006; Eden et al., 2006; Khaira et al., 2006; Mikhail et al., 2006; Boorjian et al., 2008) Furthermore, as for the report that obesity and prostatic capacity influence an OT and PSM, BCR. Tewari et al. reported overall PSM rates worldwide as follows: $24.2 \%$ ORRP, $20.4 \%$ LRP and 16.2\% RALP. (Tewari et al., 2012) Obese patients can present with more aggressive cancer. Several large series have shown that a higher BMI is associated with higher grade tumors and an increased risk of BCR after RP. (Amling et al., 2004; Freedland et al., 2004) Prolonged OT is known to be associated with an increased risk of PSM. (Secin et al., 2008; D'Alonzo et al., 2009)

BMI and prostate size are participated in PSM and OT in RP. Increasing BMI has been correlated in the literature with a higher likelihood of PSM and capsular incision in ORRP,LRP and RALP. (Freedland et al., 2005; Jayachandran et al., 2008) Also, recently in Japan, men with an increased BMI appeared at higher risk of BCR. (Komaru et al., 2010). And, recent study reported that OT increased and estimated blood loss was greater for overweight or obese patients compared with normal weight patients. (Chang et al., 2004; Chang et al., 2007; Herman et al., 2007; Lloyd et al., 2009) Furthermore, Frota et al. found a higher incidence of PSM in patients with prostates $\leq 30 \mathrm{~g}(\mathrm{P}=0.03)$ in 2008. (Frota et al., 2008) As described above, there are many reports when the BMI and prostate size participate in OT and PSM. In this study, prostate bleeding after biopsy for prostatic gland is a stronger predictor of prolonging OT and PSM than BMI and prostatic volume. Some reports suggested that in the era of robotic surgery, the degree of post biopsy hemorrhage observed in preoperative MR imaging may be predictive of surgical difficulty for performing RALP. Such finding provides concrete evidences that aftereffects of prostate biopsy indeed have significant impact on performing RALP. Recently, Martin et al. (2009) reported that RALP performed within 6 weeks of biopsy was associated with a greater risk of complication and transfusion than those done later. On their results mentioned that obliteration of surgical planes caused by prostate biopsy might lead to increased blood loss and difficult visualization, making fine points of RALP procedure more difficult. Even though assessed primary variable of interest was different (interval from biopsy $v s$. degree of hemorrhage seen on MR imaging), the results of current investigation demonstrated that aftereffects of prostate biopsy may well significantly influence surgical difficulty of RALP. It is suggested that prostate compression after prostate biopsy might help more accurately stage $\mathrm{PCa}$ because of the reduction in intraprostatic hemorrhage.

Therefore, we evaluated the effects of digital rectal compression in patients who underwent ultrasound-guided transrectal prostate biopsy on PCa staging using MRI. Then how may you prevent prostatic bleeding if you do it? Digital rectal compression is a well-known method for reducing rectal bleeding after prostate biopsy. Some reports suggest that it improves operation results we perform digital rectal compression, and to suppress the bleeding. First, rectal compression may reduce surgical difficulty. Some authors have reported that post biopsy hemorrhage may induce operative difficulty. Hong, et al. reported that the degree of post biopsy hemorrhage detected by MR image has a significant association with operative outcome such as operative time, estimated blood loss, and return of erectile function in patients who received RALP. (Hong et al., 2010) Second, some authors have argued that conventional MRI is significantly affected by the amount of post biopsy hemorrhage. (White et al., 1995; Kaji et al., 1998)

Rectal compression may shorten the period during which there is interference in the interpretation of the prostate by conventional MRI. It is very important that we compress digital rectal for the patients after biopsy in particular. It is supposed a lot of reports that the examination of MRI after the prostatic biopsy adversely affects a diagnosis now. However, it is necessary to be careful about stump excision enough when I operate for a case when prostatic bleeding remains and am under the medical treatment.

In conclusion, Our findings in the present cohort help equip surgeons pay attention to operate especially for those who experienced deferred prostatic bleeding. 
Prostatic Bleeding after Biopsy Effects Oncological Outcomes with Laparoscopic Radical Prostatectomy

Kaplan-Meier analysis shows a significant biochemical recurrence-free survival advantage of without prostate bleeding.

\section{Acknowledgements}

TI conceived of the study, and participated in its design and coordination and helped to draft the manuscript.

KK and NI participated in the design of the study and performed the statistical analysis. TT, TM, YY, TU, KS, NT, KM, HU, KT, HN, and SK carried out the operation assistant and date acquisition. HA approved it in the last of the article manuscript.

\section{References}

Abbou CC, Salomon L, Hoznek A, et al (2000). Laparoscopic radical prostatectomy: preliminary results. Urol, 55, 630-4.

Amling CL, Riffenburgh RH, Sun L, et al (2004). Pathologic variables and recurrence rates as related to obesity and race in men with prostate cancer undergoing radical prostatectomy. J Clin Oncol, 22, 439-45.

Boczko J, Madeb R, Golijanin D, et al (2006). Robot-assisted radical prostatectomy in obese patients. Can J Urol, 13, 3169-73.

Boorjian SA, Crispen PL, Carlson RE, et al (2008). Impact of obesity on clinicopathologic outcomes after robot-assisted laparoscopic prostatectomy. J Endourol, 22, 1471-6.

Brown JA, Rodin DM, Lee B, et al (2005). Laparoscopic radical prostatectomy and body mass index: an assessment of 151 sequential cases. $J$ Urol, $\mathbf{1 7 3}, 442-5$.

Chang IH, Byun SS, Hong SK, et al (2007). Assessing the body mass index of patients might help to predict blood loss during radical retropubic prostatectomy in Korean men. BJU Int, 99, 570-4.

Chang SS, Duong DT, Wells N, et al (2004). Predicting blood loss and transfusion requirements during radical prostatectomy: the significant negative impact of increasing body mass index. J Urol, 171, 1861-5.

D’Alonzo RC, Gan TJ, Moul JW, et al (2009). A retrospective comparison of anesthetic management of robot-assisted laparoscopic radical prostatectomy versus radical retropubic prostatectomy. J Clin Anesth, 21, 322-8.

Eden CG, Chang CM, Gianduzzo T, et al (2006). The impact of obesity on laparoscopic radical prostatectomy. BJU Int, 98, 1279-82.

Freedland SJ, Aronson WJ, Kane CJ, et al (2004). Impact of obesity on biochemical control after radical prostatectomy for clinically localized prostate cancer: a report by the Shared equal access regional cancer hospital database study group. $J$ Clin Oncol, 22, 446-53.

Freedland SJ, Grubb KA, Yiu SK, et al (2005). Obesity and capsular incision at the time of open retropubic radical prostatectomy. J Urol, 174, 1798-801.

Frota R, Turna B, Santos BM, et al (2008). The effect of prostate weight on the outcomes of laparoscopic radical prostatectomy. BJU Int, 101, 589-93.

Herman MP, Raman JD, Dong S, et al (2007). Increasing body mass index negatively impacts outcomes following robotic radical prostatectomy. Jsls, 11, 438-42.

Hong SK, Kim DS, Lee WK, et al (2010). Significance of postbiopsy hemorrhage observed on preoperative magnetic resonance imaging in performing robot-assisted laparoscopic radical prostatectomy. World J Urol, 28, 721-6.

Jayachandran J, Aronson WJ, Terris MK, et al (2008). Obesity and positive surgical margins by anatomic location after radical prostatectomy: results from the shared equal access regional cancer hospital database. BJU Int, 102, 964-8.

Kaji Y, Kurhanewicz J, Hricak H, et al (1998). Localizing prostate cancer in the presence of postbiopsy changes on MR images: role of proton MR spectroscopic imaging. Radiol, 206, 785-90.

Khaira HS, Bruyere F, O'Malley PJ, et al (2006). Does obesity influence the operative course or complications of robotassisted laparoscopic prostatectomy. BJU Int, 98, 1275-8.

Komaru A, Kamiya N, Suzuki H, et al (2010). Implications of body mass index in Japanese patients with prostate cancer who had undergone radical prostatectomy. Jpn J Clin Oncol, 40, 353-9.

Lloyd JC, Banez LL, Aronson WJ, et al (2009). Preoperative predictors of blood loss at the time of radical prostatectomy: results from the SEARCH database. Prostate Cancer Prostatic Dis, 12, 264-8.

Martin GL, Nunez RN, Humphreys MD, et al (2009). Interval from prostate biopsy to robot-assisted radical prostatectomy: effects on perioperative outcomes. BJU Int, 104, 1734-7.

Mikhail AA, Orvieto MA, Billatos ES, et al (2006). Roboticassisted laparoscopic prostatectomy: first 100 patients with one year of follow-up. Urol, 68, 1275-9.

Schuessler WW, Schulam PG, Clayman RV, et al (1997). Laparoscopic radical prostatectomy: initial short-term experience. Urol, 50, 854-7.

Secin FP, Jiborn T, Bjartell AS, et al (2008). Multi-institutional study of symptomatic deep venous thrombosis and pulmonary embolism in prostate cancer patients undergoing laparoscopic or robot-assisted laparoscopic radical prostatectomy. Eur Urol, 53, 134-45.

Tewari A, Sooriakumaran P, Bloch DA, et al (2012). Positive surgical margin and perioperative complication rates of primary surgical treatments for prostate cancer: a systematic review and meta-analysis comparing retropubic, laparoscopic, and robotic prostatectomy. Eur Urol, 62, 1-15.

White S, Hricak H, Forstner R, et al (1995). Prostate cancer: effect of postbiopsy hemorrhage on interpretation of MR images. Radiol, 195, 385-90. 